\title{
Switchgrass: a Valuable Biomass Crop for Energy
}

\author{
David Bransby
}

Published online: 28 June 2012

(C) Springer Science+Business Media, LLC 2012

I have been involved in research on switchgrass for 25 years, and currently teach a course on "Bioenergy and the Environment" to both undergraduate and graduate students. When asked to review this new 209-page documentation and analysis of work on switchgrass, I wondered whether there was enough scientific information on the topic to justify such a publication. My review certainly eliminated that concern: the first chapter indicates that from 1930 to 2010 , over 1,600 CAB-indexed reports referenced switchgrass, and more than half of these appeared after 1997. In addition, a quick tally revealed that on average there were 90 references cited for each of the eight chapters in the book.

The editor, Andrea Monti, assembled a group of distinguished authors who have not only provided comprehensive documentation of research conducted on switchgrass, but also unique and valuable analyses of this information that have not been published elsewhere. In addition, recognizing the origin and strong focus of research on switchgrass in the USA, the contributions from Europe are both remarkable and refreshing. Of particular significance is that researchers in Europe seem to be ahead of the USA in the essential step towards switchgrass commercialization which involves field scale studies that go beyond small plots (which typically overestimate yield from commercial-scale fields), and European authors also provide a strong contribution in the field of switchgrass physiology. The book emphasizes that biomass yield is not the only factor to consider when choosing a cellulosic biomass crop, and that other factors, especially establishment costs, are also critically important. When all the important traits for a cellulosic

D. Bransby $(\bowtie)$

Auburn University,

Auburn, AL, USA

e-mail: bransdi@auburn.edu energy crop are considered together, it is evident that switchgrass is a very strong candidate even though alternative crops may provide higher yields.

The first chapter of the book by Parrish, Casler and Monti on "The Evolution of Switchgrass as an Energy Crop" provides valuable background and makes fascinating reading, while the second on "Switchgrass Breeding, Genetics and Genomics" by Casler provides a thorough, insightful analysis of the enormous potential for genetic improvement of this extremely diverse crop with modern breeding and genetic engineering technology that might be expected from a widely recognized plant geneticist. In chapters 3 and 4 Zegada-Lizarazu et al. and Sanderson et al. provide comprehensive documentation and analysis of progress in the fields of "Crop Physiology" and "Crop Management of Switchgrass," respectively, while the status of "Switchgrass Harvest and Storage" research and development is summarized in detail by Mitchell and Schmer in chapter 5. Progress in research on "Environmental Impacts of Switchgrass Management for Energy Production" and "Biochemical and Thermochemical Conversion of Switchgrass to Biofuels" is documented and analyzed in chapters 6 and 7 by Skinner et al. and Balan et al., respectively. The book concludes with chapter 8 in which Turhollow and Epplin provide a useful analysis for "Estimating Region Specific Costs to Produce and Deliver Switchgrass," and a helpful index.

In summary, this book is definitely a milestone on the path of switchgrass to commercialization for production of cellulosic biomass. It is a recommended reference for anyone who has an interest in switchgrass, regardless of whether or not they have any experience or knowledge of this crop which is expected to make an important contribution to the emerging bioenergy industry. Without question, it will be recommended reading for my undergraduate students, and required reading for my graduate students. 